\title{
Recording of deaths in hospital information systems: implications for audit and outcome studies
}

\author{
Jane Henderson, Michael J Goldacre, Myfanwy Griffith, Hugh Simmons
}

\begin{abstract}
Study objective-The aim was to report on the extent to which death certificates which specify that death occurred in hospital can be matched and linked with routine hospital inpatient information systems.

Design-The study involved linkage of hospital records which specified that death occurred in hospital to corresponding death certificates; and linkage of death certificates which specified that death occurred in hospital to corresponding hospital records.

Setting-Six health districts in southern England covered by medical record linkage.

Subjects-Records were examined of patients aged 65 years and over, which specified that death occurred in hospital between 1979 and 1985.
\end{abstract}

Main results $-98.2 \%$ of hospital record abstracts which specified that death occurred in hospital were linked by our standard computer-based techniques to death certificates. Conversely, however, only $94.4 \%$ of death certificates which specified that death occurred in hospital could be linked to the abstracts of corresponding hospital inpatient records. A major factor contributing to the latter failures may be a difference of definition of what constitutes a death "following hospital admission" in patients who die shortly after arrival at hospital.

Conclusions-Linkage of hospital records to death certificates is both feasible and desirable. Error rates are generally small; but hospital inpatient record abstracts corresponding to death certificates for deaths in hospital may not invariably exist when death occurs shortly after the arrival of the patient at hospital.

District health authorities routinely receive death certificates for all deaths of residents of their district from the Registrar of Births and Deaths. However, data from these have not generally been added to clinical records or to hospital information systems such as patient administration systems, hospital activity analysis, or the hospital episode system. The linkage of death certificates to hospital information systems has considerable potential value to clinicians, research workers, and hospital administration. ${ }^{1}$ It would enable patients' files to be closed at death, improve administration of the medical records function, and preclude such administrative mishaps as sending follow up appointments to people who have died. It would also provide potential for medical audit and research. For example, case fatality rates among groups of patients can be studied, prognostic factors can be identified, and outcomes (measured as fatality rates) can be compared over time and between different locations. ${ }^{2}$ It is currently possible to use routine hospital statistics to calculate hospital fatality ratios, namely deaths in hospital for each condition of interest expressed as a percentage of all hospital admissions for the condition. However, by definition these miss deaths which occur after patients' discharge from hospital. Even when this limitation is accepted, it is important to recognise in comparing hospitals that such ratios may also be substantially influenced by patients' duration of stay: patients who are discharged early or transferred prior to death will not be counted in the numerator for the hospital fatality ratio relating to the hospital of first admission. ${ }^{34}$

The reliability of the hospital fatality ratio is also dependent, of course, on the accuracy of recording of the fact of death on the hospital inpatient record abstract. A number of studies have compared diagnostic data between hospital records and death certificates and have reported on the extent of discrepancies between them. ${ }^{5-8}$ In addition to this, we know from record linkage that there may be discrepancies in recording the fact of death in hospital: deaths which, according to death certificates, occurred in hospital may be selectively missing from hospital statistics. The aim of this study was to quantify this problem in the course of a study of elderly patients who died in hospital.

\section{Methods}

The Oxford record linkage study (ORLS) includes brief abstracts of records of hospital care, similar to the hospital activity analysis and the hospital episode system elsewhere in England, and death certificates which can be linked together to form person based records of hospital admissions and death. The analysis reported in this paper covered deaths of people aged 65 years and over which occurred in National Health Service general hospitals in the six districts covered by the Oxford record linkage study between 1979-85.

In the Oxford record linkage study records are matched and linked by comparing patients' surnames and forenames using modified Soundex methods, dates of birth, sex, place of birth, general practitioner, and the first eight characters of the address. A weighting system is used to estimate the probability that two records belong to the same person. This places greater importance on variables such as name and date of birth than variables such as address which, of course, may change. Our methods of matching have been described in detail 
elsewhere. ${ }^{9}$ We use the term "matching" to denote the computer process of comparing identifiers on records to determine whether two records relate to the same individual and the term "linkage" to refer to the process of bringing the two records together in computer file construction. ${ }^{9}$ Nowadays record matching is undertaken by computer and a matchweight score is generated. The score is used to divide all possible pairs of records into those which are deemed not to relate to the same person, those deemed to relate to the same person, and those where doubt exists. In circumstances of doubt about whether two records relate to the same person, clerical checks are made.

A death in hospital should be recorded both on the abstract of the hospital admission record (eg, the hospital episode system) by means of a disposal code indicating death, and on the death certificate which, on the same date, should specify the hospital in which death occurred. We therefore selected records on which the death certificate and/or the hospital disposal code indicated death in hospital. We investigated, first, the proportion of deaths in hospital as indicated by the disposal code on the inpatient discharge record which matched to a death certificate; and, secondly, the proportion of deaths in hospital as indicated by the place of death code on the death certificate which matched to a hospital discharge record. In this investigation a "match" for the event in which death occurred was first defined narrowly to include pairs of records for which the hospital discharge record and the death certificate gave the same date and hospital at the time of death. Next, a "match" was defined more broadly to allow a discrepancy in dates of death of up to three days and to allow for differences between the types of record in the specification of the hospital. Following this, an investigation was undertaken of possible reasons
Table I Numbers (and percentages) of deaths in hospital as indicated by disposal code on discharge which were matched to a death certificate by various criteria.

Table II Numbers (and percentages) of deaths in hospital as indicated by death certificate which were matched to corresponding inpatient record by various criteria.

\begin{tabular}{lll}
\hline $\begin{array}{l}\text { Total number of deaths in hospital as } \\
\text { indicated by disposal code on discharge }\end{array}$ & $50023(100.0)$ \\
$\begin{array}{l}\text { Hospital discharge and death certificate match; } \\
\text { same hospital, same date of death }\end{array}$ & 47207 (94.4) \\
$\begin{array}{l}\text { Hospital discharge and death certificate } \\
\text { match; any hospital, allowing up to three days } \\
\text { difference in date of death }\end{array}$ & $48923 \quad(97.8)$ \\
$\begin{array}{l}\text { Hospital discharge and death certificate match; } \\
\text { any hospital, any date of death }\end{array}$ & $49136 \quad(98.2)$ \\
\hline
\end{tabular}

Total number of deaths in hospital as

indicated by death certificate

Hospital discharge and death certificate match, same hospital, same date of death

Hospital discharge and death certificate match;

any hospital, allowing up to three days

difference in date of death

Hospital discharge and death certificate match any hospital, any date of death
Table III Analysis of categories when death certificates matched abstracts of hospital inpatient records within four days of death: number of records in each category ( $n$ ) and number and percentage which matched.

\begin{tabular}{|c|c|c|c|}
\hline & $n$ & $\begin{array}{l}\text { No }(\%) \\
\text { matched }\end{array}$ & $\chi_{1}^{2}$ \\
\hline $\begin{array}{l}\text { Deaths aged } 65-74 \text { years } \\
\text { Deaths aged } 75 \text { years and over }\end{array}$ & $\begin{array}{l}18510 \\
38653\end{array}$ & $\begin{array}{l}15993(86.4) \\
36410(94.2)\end{array}$ & 996* \\
\hline $\begin{array}{l}\text { Deaths from myocardial infarction ( } 410) \text {, aortic } \\
\text { aneurysm ( } 441) \text {, injury and poisoning (ch XVII) } \\
\text { Deaths from other causes }\end{array}$ & $\begin{array}{r}8856 \\
48307\end{array}$ & $\begin{array}{r}7324(82.7) \\
45079(93.3)\end{array}$ & $1105^{\star}$ \\
\hline $\begin{array}{l}\text { Deaths from malignant neoplasms } \\
\text { Deaths from other causes }\end{array}$ & $\begin{array}{l}13124 \\
44039\end{array}$ & $\begin{array}{l}12351(94.1) \\
40052(90.9)\end{array}$ & $132^{\star}$ \\
\hline $\begin{array}{l}\text { Coroner's verdict of death by accident or misadventure } \\
\text { No inquest or other verdict }\end{array}$ & $\begin{array}{r}413 \\
56750 \\
\end{array}$ & $\begin{array}{r}273(66.1) \\
52130(91.9)\end{array}$ & $356^{\star}$ \\
\hline
\end{tabular}

${ }^{\star} \mathrm{p}<0.001$ for failures to match by analysing the matching rate of the records in various ways described below.

\section{Results}

In the record files used in this study a death in hospital was recorded in 50023 hospital discharge records. Of these, $49136(98.2 \%)$ had a matching death certificate (table I). The match was not always precise in respect of the variables studied: the hospital and date of death matched exactly for only $94.4 \%$ of the hospital records. However, allowance for some discrepancy in these two variables resulted in successive improvements to the rate of matching as shown in table I.

A death in hospital was recorded on 57163 death certificates. Using the narrow definition of a match, only 47146 certificates $(82.5 \%)$ matched with a hospital record. This improved to $90.1 \%$ allowing three days' leeway on the date of death and leeway on the specification of hospital (table II). Ninety four per cent of death certificates matched to a hospital record when dates of discharge were disregarded. This may have been the episode in which death occurred or may possibly have been a previous admission.

A further analysis was undertaken to compare the matching of death certificates to the abstracts of inpatient records in various subgroups (table III). Matching was significantly better in people aged 75 years or over than in people aged 65-74 years; in people who died from "non-sudden" causes such as malignant neoplasms than in people who died from causes of death which may be sudden such as myocardial infarction, aortic aneurysm, injuries, and poisoning; and in cases where there was a coroner's inquest and a verdict of death by accident or misadventure. This suggested that a substantial proportion of the shortfall of recording of deaths in hospital record abstracts may have been due to deaths in accident and emergency departments and those which occurred before formal admission took place.

\section{Discussion}

FROM HOSPITAL RECORDS TO DEATH CERTIFICATES: MATCHING THE FACT OF DEATH

There is probably no comprehensive routine way of testing precisely how well medical records have been matched in practice by computer in large populations. Clerical scrutiny can of course be used on random samples of records to identify those which have been brought together by computer when they do not relate to the same person. However there is no obvious way to identify random samples of records which have not been brought together when they do in fact relate to the same person. An approach to this latter problem which we have used in developing, validating, and refining record linkage techniques is to identify subsets of people who, according to their hospital record abstract, have died in hospital, and to search for the records of their death certificates. The two types of record are completed independently of one another and we believe that the level of matching found between hospital records and death certificates for patients who die in hospital should be no different from that in 
matching of hospital records of care to death certificates for patients who die subsequently outside hospital.

The great majority of admissions in which the patient died in hospital in our study $(98.2 \%)$ had a matching death certificate on file although it is clear from table I that a small amount of tolerance on the dates and place of death was required in matching. In our experience, records of elderly people (aged 65 years or over) are generally harder to match than those for the young, mainly because the recording of identifiers on different records (such as forenames and dates of birth) tend to be rather more variable in the elderly. It is also possible that, in a few cases, the disposal code which specified death on the hospital record abstract was wrong and the person was discharged alive.

FROM DEATH CERTIFICATES TO HOSPITAL RECORDS: MATCHING THE PLACE OF DEATH

The proportion of death certificates with a matching hospital record abstract was not so complete. Ninety per cent of deaths matched allowing up to three days' difference in dates of death and variations in details about the hospital at the time of death. The possible reasons for the failure to match the remaining $10 \%$ are either (1) that the hospital discharge record carried very different identifying information from that on the death certificate, or (2) that the hospital admission was not recorded. The first of these happens sometimes because the informant at death (usually a relative) supplies different information regarding personal details from that given by the patient in hospital. A certain degree of divergence between identifying variables is allowed in matching and linkage in ORLS but, beyond that, two records are considered to relate to different people. ${ }^{9}$ This is probably the main cause of the $1.8 \%$ of deaths in hospital (as indicated by hospital disposal code) without a matching death certificate (table I). A similar percentage of death certificates without a matching hospital record (table II) is probably accounted for in the same way.

The second reason for a hospital event to be missing from the files is if it was never recorded. Over the years covered by this study, routine comparisons have been made between numbers of inpatient records in the Oxford record linkage study each year and the corresponding $\mathrm{SH} 3$ returns which are independent counts of numbers of hospital inpatients. Correspondence is very close and the "failure to match" is therefore not a general one of missing hospital records. It is, as the comparison between tables I and II indicates, mainly a result of missing records when the death certificate states that the patient died in hospital. Further evidence of discrepancies between numbers of deaths in hospital recorded in hospital systems and on death certificates can be deduced from national published statistics. The annual Hospital inpatient enquiry included data on the number of deaths recorded in hospital each year in its sample. ${ }^{10}$ Published national mortality statistics include tabulations of the number of deaths in hospital as recorded on death certificates each year. ${ }^{11}$ The latter number is consistently higher than the former. It is known that sometimes there are shortfalls in recording hospital episodes which end in death because case notes for such patients may be less readily available. ${ }^{12}$ This was sometimes a problem in regions where the hospital activity analysis record was initiated after the patients' discharge or death (rather than on admission). Selective omission of episodes which end in death should not occur in the present era in which the computer record is initiated at the time of admission. ${ }^{13} \mathrm{~A}$ more intractable problem is that of the designation of an "admission". It is recognised that there is some ambiguity about when admission takes place. This has been formally defined as "when the patient is physically present, clinical responsibility has been accepted for him/her, and he/she has made contact with the organisation". ${ }^{14}$ In practice, if a patient is admitted through an accident and emergency department, the formal admission record tends to be completed when the patient reaches the ward. The number and proportion of such patients who die before being formally admitted may vary from one hospital to another. This possibility should be considered when hospital fatality ratios are calculated from the recording of death on the hospital episode system alone.

Linkage of hospital records and death certificates is both feasible and desirable to increase administrative efficiency and to aid medical research. In practice, it should be straightforward in districts where the majority of patients receive hospital care in the district. In areas where there is considerable cross boundary care it would, of course, be more problematic. Such problems will greatly reduce when the Department of Health's plans for information systems based on resident populations are implemented. ${ }^{15}$

The Unit of Health-Care Epidemiology is part of the Department of Public Health and Primary Care, University of Oxford. The Unit is funded by the Department of Health. Michael Goldacre is director of the Oxford record linkage study, data collection for which is funded by Oxford Regional Health Authority.

1 Rang EH, Acheson ED, O'Connor BT. Clinical significance of deaths after discharge from hospital unrecorded in the hospital notes. Lancet 1968; ii: 908-10.

2 Goldacre MJ, Seagroatt V. Case-fatality rates as measures of outcome: studies using medical record linkage. In: Robbins $\mathrm{D}$, Walters $\mathrm{A}$, eds. $\mathrm{DH}$ yearbook of research and developmen 1990. London: HMSO, 1990.

3 Acheson ED. The incidence and prognosis of fracture of the femoral neck. Oxford: Unit of Clinical Epidemiology, University of Oxford, Report No R17, 1968.

4 Goldacre MJ. Hospital inpatient statistics: some aspects of interpretation. Community Med 1981; 3: 60-68.

5 Medical Services Study Group of the Royal College of Physicians of London. Death certification and epidemiological research. $B M F$ f 1978; ii: 1063-5.

6 Goldacre MJ. Accuracy of death certification for acute bacterial meningitis. Public Health 1977; 91: 279-81.

7 Folsom AR, Gomez-Marin O, Gillum RF, Kottke TE, Lohman W, Jacobs DR. Out-of-hospital coronary death in an urban population-validation of death certificate diagnosis. urban population-validation of death

Am f Epidemiol 1987; 125: 1012-8.
8 Alderson MR, Meade TW. Accuracy of diagnosis on death certificates compared with that in hospital records. Br $\mathcal{F}$ Prev Soc Med 1967; 21: 22-9.

9 Gill LE, Baldwin JA. Methods and technology of record linkage: some practical considerations. In: Baldwin JA, Acheson ED, Graham WJ, eds. Textbook of medical record linkage. Oxford: Oxford University Press, 1987.

10 Department of Health and Social Security, Office of Population Censuses and Surveys, Welsh Office. Hospital in-patient enquiry. London: HMSO, annual until 1986.

11 Office of Population Censuses and Surveys. Mortality statistics: general. Series DH1. London: HMSO, annual.

12 Rosser R. Discrepancies in hospital data. Lancet 1972; i: 1070.

13 Department of Health and Social Security. Steering group on health services information (Chairman: Mrs E Korner). First Report to the Secretary of State. London: HMSO, 1982:
27-8.

National Health Service Corporate Data Administration. Definition request. Birmingham: NHS Corporate Data Administration, 1989

15 Department of Health. Working for patients. Framework for information systems: the next steps. London: HMSO, 1990 informa 